\title{
Molecular Simulation of Resin and the Calculation of Molecular Bond Energy
}

\author{
Tian Liang, Zhao-Wen Zhan, and Yan-Rong Zou*
}

Cite This: ACS Omega 2021, 6, 28254-28262

Read Online

ABSTRACT: In this study, average structural characteristics of amber were researched and used as an example to establish the three-dimensional (3D) average structure of resin. Two coal samples containing solid amber were collected from Fushun and Hunchun in Northeast China, from which pure amber samples were separated and resin was extracted. Solid-state nuclear magnetic resonance $\left({ }^{13} \mathrm{C}\right.$ NMR) spectroscopy was used to obtain structural information of amber, and matrix-assisted laser desorption ionization time-of-flight mass spectrometry was performed on the resins to determine their molecular mass. The results of these studies revealed that the average structure of amber was dominated by cycloalkane, with a small amount of aromatic carbon, and there were almost no aliphatic chains in the structure. The molecular masses of the compounds in the resin were mainly in the range 99-750 Da, and the average molecular mass was $\sim 370 \mathrm{Da}$. To characterize the resin chemical structure, two 3D molecular models based on density functional theory were established taking amber as the example, and the relevant molecular bond energies were calculated. Based on these models, the interactions among the components in oil were studied, and the binding energies of the different molecules were calculated.

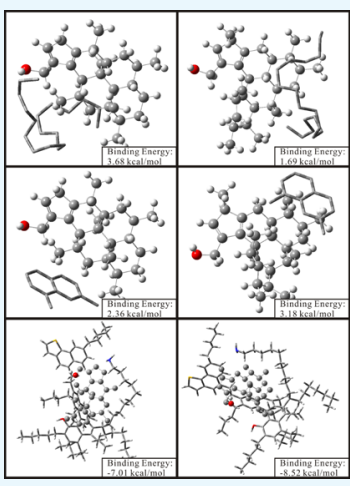
In summary, in this study, amber was used as a medium to establish an accurate molecular model of resin and proved that compared to hydrocarbon compounds, resin molecules were more likely to interact with bitumen.

\section{INTRODUCTION}

Resin is an important part of crude oil, and since its first separation from petroleum, researchers have paid increasing attention to its properties. ${ }^{1,2}$ It has a pale-to-dark yellow appearance and is more soluble in organic solvents like dichloromethane than hydrocarbon compounds (saturates, aromatics) present in petroleum. ${ }^{1,3,4}$ At room temperature, resin is viscous and has weak fluidity; its chemical properties can influence petroleum properties and migration. ${ }^{3,5,6}$

To clarify the microstructure characteristics of resin, there has been some research on the resin molecular structure. For example, Bava studied the different types of sulfur functional groups in resin by X-ray absorption near-edge structure, ${ }^{7}$ while Klein researched the distribution of heteroatom compounds in resin by Fourier transform ion cyclotron resonance mass spectrometry. ${ }^{8-10}$ Both resin and asphaltene are macromolecular components found in petroleum. Nuclear magnetic resonance (NMR) is an important analysis method to study the composition of petroleum, and many researchers have investigated the interaction between resin and asphaltene. ${ }^{11-14}$ Mousavi and Wang simulated the interactions between four crude oil components based on density functional theory (DFT). ${ }^{15,16}$

In recent decades, molecular simulation study of organic geologic matter has received widespread attention. ${ }^{17-21}$ Different types of kerogen and asphaltene molecular models have been established, ${ }^{18,22,23}$ and the asphaltene molecular model has been studied in great detail. ${ }^{17,19,24,25}$ Murgich established the basic resin molecular structure using oil sand and organic solvents (such as n-octane and toluene). ${ }^{26,27}$ Coelho reported four kinds of resin molecular models by studying the aliphatic chains of resin. $^{28}$ Fourier transform infrared spectroscopy (FT-IR) and NMR spectroscopic studies were conducted by $\mathrm{Li}$ to detect resin, and the results were used to simulate a Liaohe heavy oil resin structural model. ${ }^{29}$ However, compared with kerogen, research on resin structure is still in its infancy, and there have been fewer studies on the resin chemical structure model. Furthermore, there are a few reports on the relative range of the resin molecular mass, and most resin molecular models are based on experience or comparison with asphaltene molecules. $^{28,29}$ This is gradually becoming a critical flaw in the study of resin.

Instrumental methods have limitations because of the colloidal property of resin; thus, many detection methods, including solid-state NMR, cannot be applied to resin, and there is no effective verification method once a structure is established. $^{26-29}$ However, as a complex heteroatom compound, resin molecular characteristics are difficult to describe with a single compound. ${ }^{28,29}$ Additionally, how to establish an average molecular structure has become a pressing issue.

Received: August 12, 2021

Accepted: October 1, 2021

Published: October 13, 2021 
Table 1. Organic Element Content and Relative Atomic Number of Amber and Resin Samples

\begin{tabular}{|c|c|c|c|c|c|c|c|c|c|c|}
\hline \multirow[b]{2}{*}{ sample ID } & \multicolumn{2}{|c|}{$\mathrm{C}$} & \multicolumn{2}{|c|}{$\mathrm{H}$} & \multicolumn{2}{|c|}{$\mathrm{O}$} & \multicolumn{2}{|c|}{$\mathrm{N}$} & \multicolumn{2}{|c|}{$S$} \\
\hline & $P^{a} \%$ & $R^{b}$ & $P \%$ & $R$ & $P \%$ & $R$ & $P \%$ & $R$ & $P \%$ & $R$ \\
\hline FS amber & 86.94 & 100.00 & 10.29 & 142.00 & 2.68 & 2.31 & 0.08 & 0.08 & 0.01 & 0.00 \\
\hline FS resin & 82.40 & 100.00 & 9.11 & 132.61 & 5.09 & 4.63 & 0.16 & 0.17 & 3.24 & 1.47 \\
\hline $\mathrm{HC}$ amber & 86.57 & 100.00 & 10.85 & 147.73 & 2.52 & 2.14 & 0.06 & 0.06 & 0.00 & 0.00 \\
\hline $\mathrm{HC}$ resin & 83.43 & 100.00 & 9.72 & 139.87 & 6.35 & 5.71 & 0.10 & 0.11 & 0.40 & 0.18 \\
\hline
\end{tabular}

${ }^{a}$ Organic element content of samples. ${ }^{b}$ Relative atom number per 100 carbon atoms in samples.

Therefore, in this research, amber can be used for solid-state NMR studies because it has more stable properties than resin and provides an analogue for establishing an average resin structure.

To make up for the lack of detection methods, amber was selected to represent the resin for relative analysis in this study. Amber is another natural organic macromolecular geological matter and is derived from resin under geological action. ${ }^{30}$ In recent years, the chemical structures of most amber compounds have been resolved by researchers. ${ }^{31,32} \mathrm{GC} / \mathrm{MS}$ and PY/GC/ MS, techniques used to detect complex organic matter, were used to identify the fragment structure in amber, and it was found that amber contains a large amount of aromatic compounds like amberene, homoamberene, and trimethyltetralin. ${ }^{33-37}$ Especially in 1992, Anderson divided the resinites into four categories according to pyrolysis compounds. Class I and Class II were derived from polymers of labdatriene (diterpenoid) carboxylic acids and sesquiterpenoid hydrocarbons, respectively. Class III and Class IV were natural polystyrenes and sesquiterpenoids. The detailed molecular fragment information for the research of amber is provided. ${ }^{38}$ According to previous research, amber and resin are similar in structure. ${ }^{39,40}$ Both are composed of several short aliphatic chains and small aromatic ring clusters. ${ }^{39}$ Amber exists as a solid under normal conditions, and its main component is resin. ${ }^{41}$ Therefore, the structure of amber can be used to approximate the average resin structural model.

In this study, two amber samples were separated from Hunchun (HC) and Fushun (FS) coals. Solid-state ${ }^{13} \mathrm{C}$ NMR spectroscopy was used to obtain the chemical information of amber. FT-IR was used to detect the functional groups and compare the difference between the chemical structures of amber and resin. ${ }^{42-44}$ Due to the similarity between amber and resin structures, in this study, we used amber structural characteristics as the basic parameter to establish the resin structure. Two-dimensional (2D) structural models were established in the ACD software and were optimized to threedimensional (3D) resin structural models by DFT calculations based on Gaussian 16. While establishing a molecular model, to ensure the accuracy of the molecular mass, matrix-assisted laser desorption ionization time-of-flight mass spectrometry (MALDI TOF MS) was used to characterize the resin, which was extracted from the coal by organic solvents, and to derive the average molecular weight distribution. Based on the resin models, the binding energy between resin and other organic matter was calculated in Autodock 4.2. The purposes of this study are (1) characterization of the chemical structure of amber, (2) using amber as an example to establish average resin molecular models for a reasonable molecular mass, and (3) evaluation of the binding energy between resin molecules and other components in oil to elucidate intermolecular interactions.

\section{RESULTS AND DISCUSSION}

2.1. Organic Element Content. The proportions of the organic element are shown in Table 1. Carbon was the most dominant organic element in amber samples comprising 86.95 and $86.57 \%$ of FS and HC samples, respectively. The hydrogen contents were $10.29 \%$ in FS amber and $10.85 \%$ in HC amber. Among the heteroatoms, the highest content was oxygen, while sulfur and nitrogen were almost undetectable in the samples.

The relative numbers of atoms of each element per 100 carbon atoms are listed in Table 1 . In the chemical structure of amber, 100 carbon atoms corresponded to 142 hydrogen atoms in the FS sample and 147 hydrogen atoms in the HC sample. The number of oxygen atoms per 100 carbon atoms in the two samples was around 2, while the number of nitrogen and sulfur atoms was less than 1 .

The elemental contents of resin samples are also listed in Table 1; compared with amber, the proportion of carbon in resin was slightly lower and that of oxygen was higher. The elemental content of amber is similar to that of resin: both of them are composed of carbon-hydrogen to form the skeleton and connect part of the heteroatom functional groups. The difference is the amount of heteroatoms in resin is more than that in amber.

2.2. Molecular Mass of the Chemical Structure. The results of MALDI TOF MS are shown in Figure 1. Figure 1a

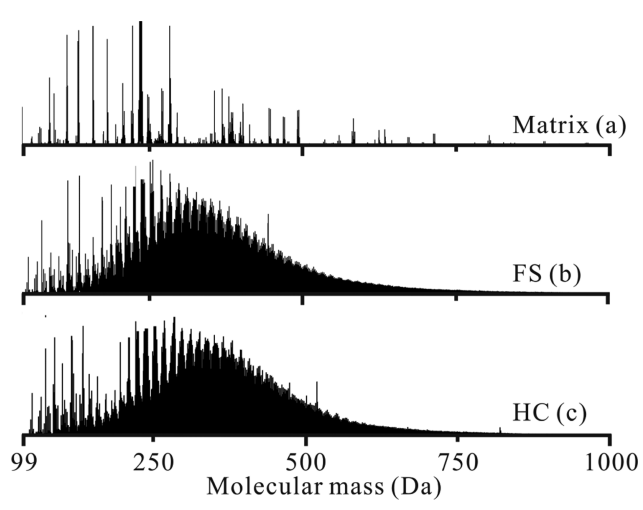

Figure 1. MALDI TOF mass spectra of the blank and resins.

shows the mass spectrum of the matrix used in the detection, while Figure $2 b, c$ shows the spectra of the FS and HC resin samples extracted from the coal samples. These spectra show that many small molecular compounds were detected in the two samples. The molecular mass of most compounds was within the range 99-750 Da. The molecular masses of most compounds in the FS and HC samples were around $370 \mathrm{Da}$. The number of compounds with molecular mass above $370 \mathrm{Da}$ decreased gradually, and compounds with molecular mass above $1000 \mathrm{Da}$ were difficult to detect in the sample. Therefore, MALDI TOF MS provided evidence of the molecular mass distribution in the 


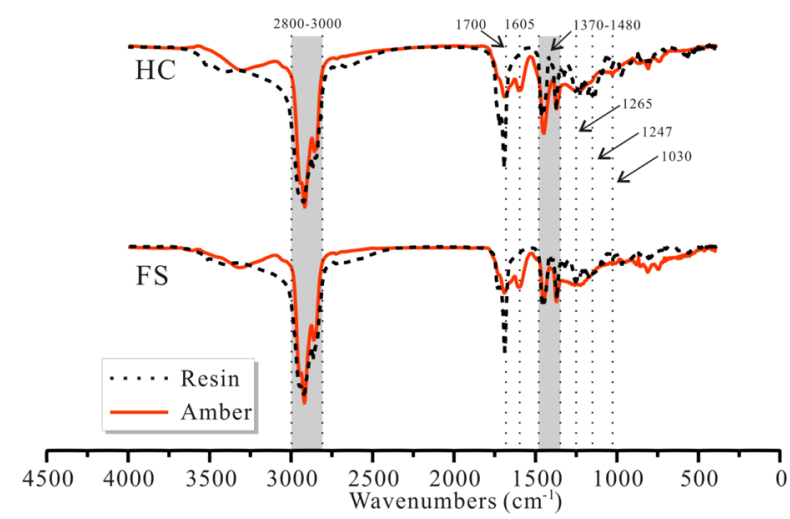

Figure 2. FT-IR spectra of amber and resin samples.

resin and provided the basic parameters of the average molecular mass. In this study, the molecular mass of the average molecular structural models of the two samples was approximately $370 \mathrm{Da}$.

2.3. Functional Groups. The composition of functional groups in amber and resin samples was detected by FT-IR, and the results are shown in Figure 2. In the figure, the aliphatic group is the majority component of four samples (FS amber, FS resin, $\mathrm{HC}$ amber, and $\mathrm{HC}$ resin). The ranges of symmetric stretching vibration of this functional group are 1370-1480 and 2800-3000 $\mathrm{cm}^{-1} \cdot{ }^{42-44} \mathrm{C}=\mathrm{O}\left(1700 \mathrm{~cm}^{-1}\right)$ stretch was detected, and this shows that there are carbonyl and carboxyl groups in samples. Bands of 1265, 1247, and $1030 \mathrm{~cm}^{-1}$ represented the phenolic $\mathrm{OH}, \mathrm{C}-\mathrm{O}-\mathrm{C}$ stretch, and asymmetric $\mathrm{C}-\mathrm{O}-\mathrm{C}$ stretch, respectively. ${ }^{42-44}$ It is worth noting that all of the above-mentioned structure units are present in ambers and resins, and the proportions of them are roughly the same (Figure 2 ). This meant that both ambers and resins have extremely high similarities in the composition of functional groups.

The only obvious difference between amber and resin under FT-IR detection is that amber contains a small amount of aromatic $\mathrm{C}=\mathrm{C}$ stretching vibration $\left(1605 \mathrm{~cm}^{-1}\right)$; however, two resin samples do not have this structural feature. ${ }^{42-44}$ This phenomenon indicated that there is a small amount of aromatic carbons contained in amber, while in resin, there are almost no complete aromatic rings. This result provides important structural information for the establishment of models.

2.4. Amber Structure Information. The structural information of amber samples was obtained from the solidstate ${ }^{13} \mathrm{C}$ NMR spectra (Figure 3 ). According to previous studies, 12 types of organic carbon functional groups can be detected by ${ }^{13} \mathrm{C}$ NMR studies, including aliphatic carbon, aromatic carbon, carboxyl carbon, and carbonyl carbon, whose chemical shifts are 5-95, 95-150, 150-185, and 185-225 ppm, respectively. ${ }^{22,45,46}$

2.4.1. Aliphatic Carbon. The proportion of each type of carbon is listed in Table 2 and Figure 4. Aliphatic carbon accounted for the largest proportion in the amber structure, exceeding $85 \%$ in both samples. The aliphatic carbon is composed of six functional types: aliphatic methyl $\left(\mathrm{f}_{\mathrm{CH} 3 \mathrm{al}}\right)$, aromatic methyl $\left(\mathrm{f}_{\mathrm{CH}_{3} \text { ar }}\right)$, methylene $\left(\mathrm{f}_{\mathrm{CH}_{2}}\right)$, methine $\left(\mathrm{f}_{\mathrm{CH}}\right)$, quaternary $\left(f_{C}\right)$, and $\mathrm{O}$-alkyl $\left(f_{\mathrm{O}}\right)$ with chemical shifts of 10-19, $19-22,22-35,35-45,45-60$, and 60-95 ppm, respectively, as Guan and Tong showed for the kerogen structure. ${ }^{4,48}$ In Table 2 , two methyl chemical shifts were 14 and 20 ppm (aliphatic methyl and aromatic methyl), the methylene chemical shift peak was $29 \mathrm{ppm}$, four chemical shift peaks $(34,38,44$, and $47 \mathrm{ppm})$ constituted the methylene group, quaternary carbon was located

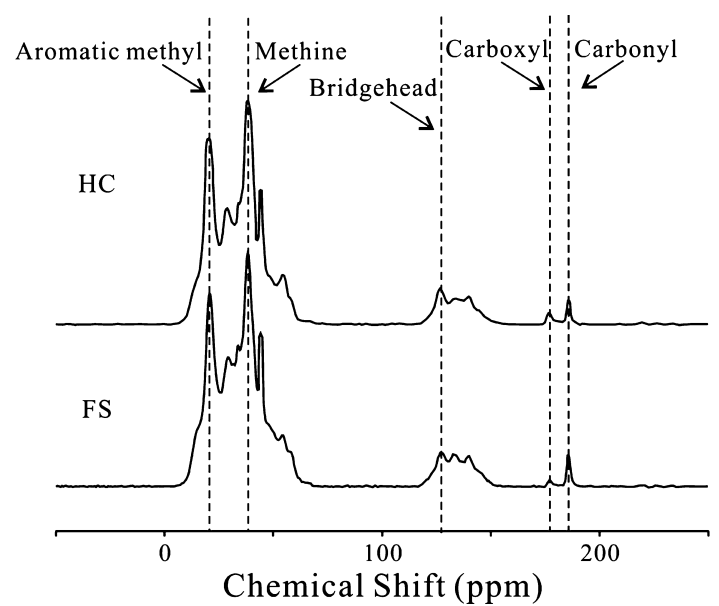

Figure 3. Solid ${ }^{13} \mathrm{C}$ NMR spectra of amber samples.

at $54 \mathrm{ppm}$, and the $\mathrm{O}$-alkyl was composed of two peaks at 58 and $64 \mathrm{ppm}$. According to the NMR results of the two samples (Figure 4), methine was the highest content aliphatic functional group with a proportion around 40\%; this was followed by methyl with $23 \%$, and methylene, the most important group of aliphatic chains, around $17 \%$. In addition, the content of quaternary carbon group in the amber chemical structure was around $3 \%$, while the content of $\mathrm{O}$-alkyl was only around $2 \%$, which was consistent with the low oxygen content in the sample. The results of the carbon functional group content analysis indicated that in the amber chemical structure, the aliphatic chains are short, and a large amount of methine represents the cycloalkane functional group. Therefore, the amber average structure models might contain several cycloalkanes and a few short aliphatic chains.

2.4.2. Aromatic Carbon and Other Functional Groups. Aromatic carbon has been classified into four types in previous studies: ${ }^{47,49}$ protonated ( $\mathrm{fH}$ a), bridgehead ( $\mathrm{fB} \mathrm{a}$ ), branched (fS a), and oxy-aromatic (fO a), with corresponding chemical shifts of 95-118, 118-135, 135-145, and 145-155 ppm, respectively. In this study, protonated aromatic carbon was not detected in the samples. Table 2 and Figure 4 show only three types of aromatic functional carbon groups: bridgehead ( $\mathrm{fB} a)$, branched (fS a), and oxy-aromatic ( $\mathrm{fO}$ a). The relative proportions of bridgehead aromatic carbon in amber samples were $4.31 \%$ (FS) and $4.20 \%$ (HC), roughly equivalent to those of oxy-aromatic carbons. Branched aromatic carbon was the least abundant aromatic functional carbon in the sample, its relative content in the two samples not exceeding 3\% (Figure 4).

Carboxyl $\left(\mathrm{f}_{\mathrm{COOH}}\right)$ and carbonyl $\left(\mathrm{f}_{\mathrm{C}=\mathrm{O}}\right)$ carbons were detected in amber samples (Table 2 and Figure 4 ). However, the contents of these two functional groups were very low, especially carboxyl, and were difficult to detect in the amber chemical structure.

2.4.3. Characteristics of the Average Chemical Structure Model. Combining the results of the three detection methods, the amber structure information was used to establish the average structure model, and the molecular mass of resin was used to standardize the model size. As summarized from the relative detection, it was found that the molecular model has the following characteristics:

(1) The model skeleton is composed of hydrogen and carbon atoms with a small number of oxygen atoms. Few oxygen 
Table 2. Carbon Parameters from ${ }^{13} \mathrm{C}$ NMR

\begin{tabular}{|c|c|c|c|c|c|}
\hline $\begin{array}{l}\text { Chemical } \\
\text { shift (ppm) }\end{array}$ & FS (\%) & $\mathrm{HC}(\%)$ & Functional group & Abbreviation & $\begin{array}{l}\text { Structure } \\
\text { schematic }\end{array}$ \\
\hline 14 & 4.65 & 4.96 & Aliphatic methyl & $\mathrm{f}_{\mathrm{CH} 3 \mathrm{al}}$ & \\
\hline 20 & 19.18 & 18.24 & Aromatic methyl & $\mathrm{f}_{\mathrm{CH} 3 \mathrm{ar}}$ & \\
\hline 29 & 17.44 & 17.14 & Methylene & $\mathrm{f}_{\mathrm{CH} 2}$ & $-\mathrm{CH}_{2}-\mathrm{CH}_{2}-\mathrm{CH}_{3}$ \\
\hline 34 & 5.45 & 6.18 & \multirow{4}{*}{ Methine } & \multirow{4}{*}{$\mathrm{f}_{\mathrm{CH}}$} & \\
\hline 38 & 21.15 & 19.87 & & & \\
\hline 44 & 3.49 & 5.98 & & & \\
\hline 47 & 10.08 & 8.40 & & & \\
\hline 54 & 3.567 & 3.21 & Quaternary & $\mathrm{f}_{\mathrm{C}}$ & \\
\hline 58 & 2.03 & 1.63 & \multirow{2}{*}{ O-alkyl } & \multirow{2}{*}{ fo } & \multirow{3}{*}{$-\mathrm{CH}_{2}-\mathrm{O}-$} \\
\hline 65 & 0.00 & 0.77 & & & \\
\hline 126 & 4.31 & 4.20 & Bridgehead & $\mathrm{f}_{\mathrm{a}}^{\mathrm{B}}$ & \\
\hline 133 & 2.37 & 2.91 & \multirow[t]{2}{*}{ Branched } & \multirow[t]{2}{*}{$\mathrm{f}_{\mathrm{a}}^{\mathrm{s}}$} & \\
\hline 140 & 3.62 & 3.33 & & & \\
\hline 145 & 1.11 & 1.29 & Oxy-aromatic & $\mathrm{f}_{\mathrm{a}}^{\mathrm{o}}$ & \\
\hline 177 & 0.36 & 0.70 & Carboxyl & $\mathrm{f}_{\mathrm{COOH}}$ & $-\overline{\mathrm{COOH} / \mathrm{R}}$ \\
\hline 185 & 1.21 & 1.20 & Carbonyl & $\mathrm{f}_{\mathrm{C}}=\mathrm{O}$ & \\
\hline
\end{tabular}

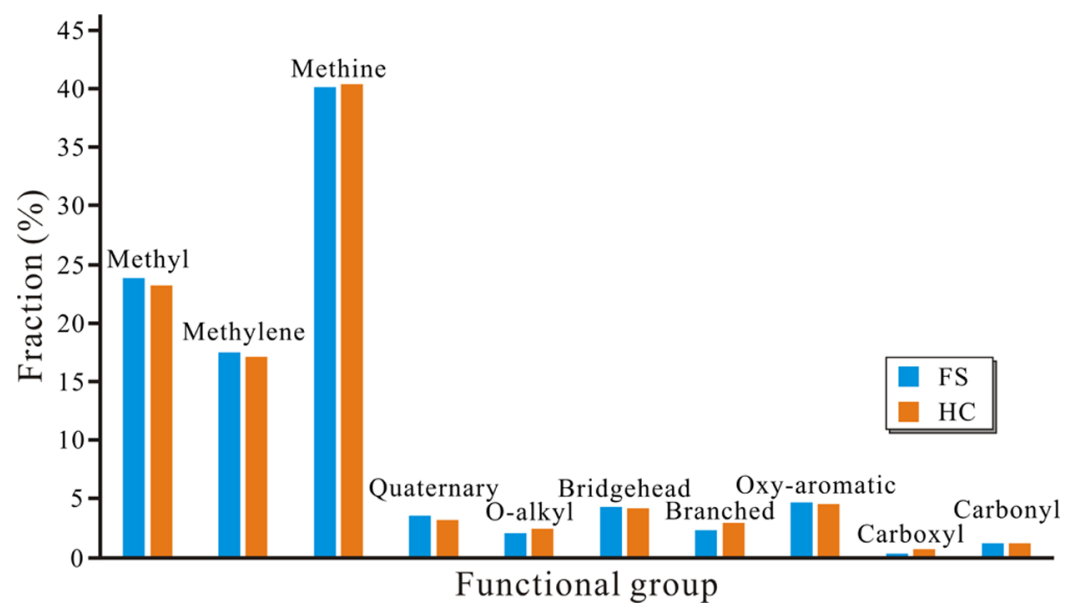

Figure 4. Functional group distribution.

atoms are attached to the carbon atoms, and carboxyl and carbonyl functional groups are rare in the amber structure.

(2) According to MALDI TOF MS, the molecular mass of the average resin structure model is approximately $370 \mathrm{Da}$, and its atomic composition includes carbon, hydrogen, and oxygen atoms. Due to the low nitrogen and sulfur contents, they are not included in the average molecular model.

(3) The proportion of aliphatic carbon is higher than that of aromatic carbon. Among the aliphatic carbons, most exist in a cycloalkane form, although there are some short aliphatic chains in the structure.

(4) The aromatic carbon content in the sample is very low, and in the average structure model, the aromatic ring structures might contain only one aromatic ring or even less. However, this does not mean that there are only small aromatic cluster structures in the sample. Larger-scale aromatic clusters can be present in the compound with larger molecular mass, but they are difficult to represent in the average structure model. 

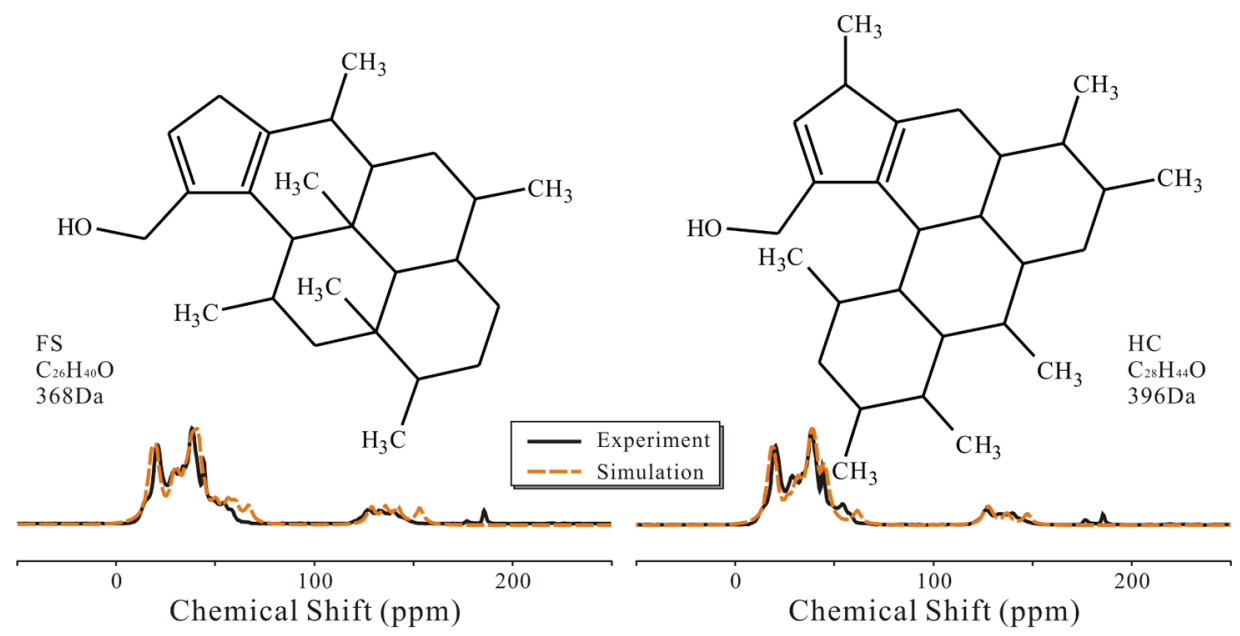

Figure 5. 2D chemical structures of resins and comparison spectra.
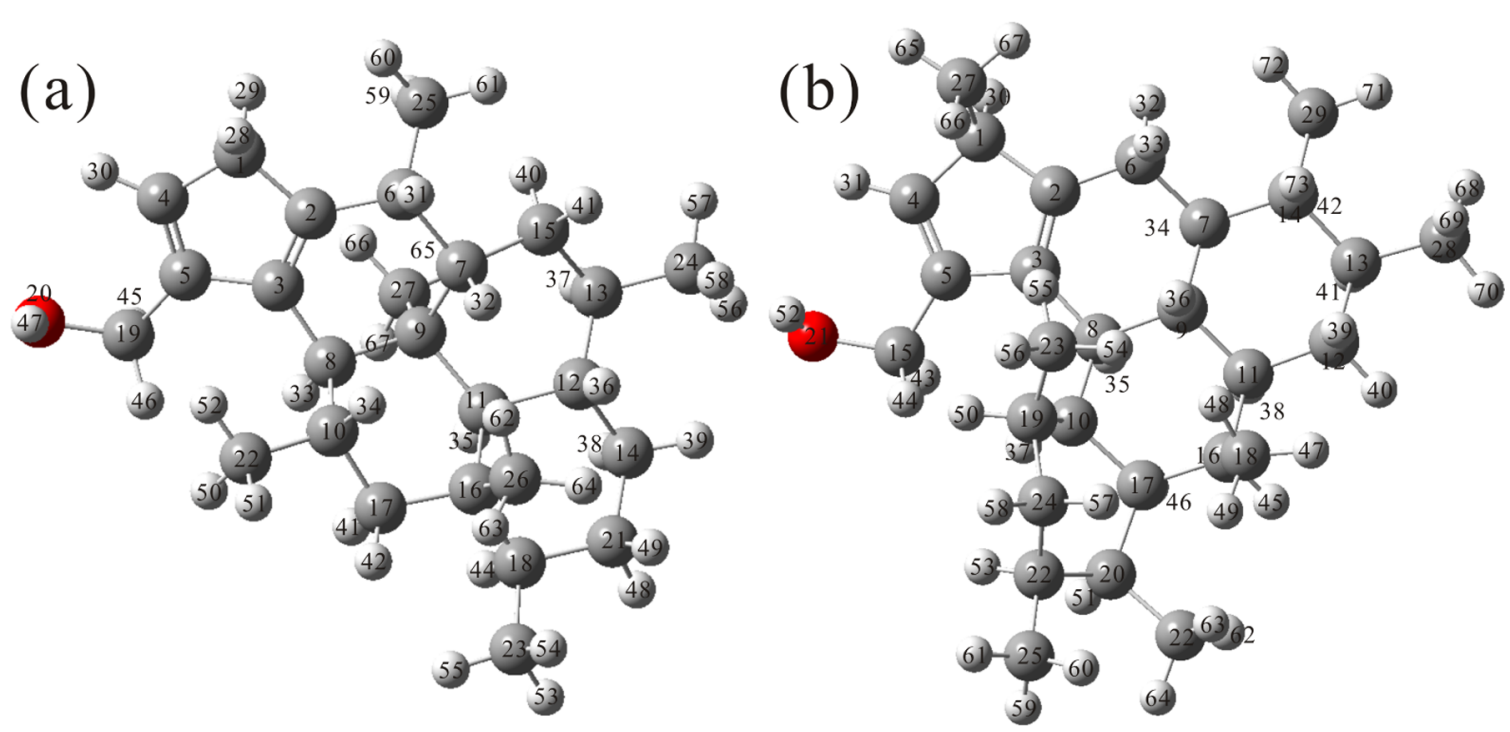

Figure 6. 3D resin molecular models. (a) Representative FS sample and (b) representative HC sample. The serial number in the model corresponds to Table 3. The hydrogen atoms of nos. 45 and 65 in (a) and nos. 42, 41, 35, and 38 in (b) are blocked behind the marked atoms. The 3D models are attached to the support material.

\subsection{Establishment of the Amber Average Structure}

Model. Based on the results of experiments, two chemical structural models were established in the ACD software, and gNMR was used to simulate the NMR spectra of models as in our previous work. ${ }^{20,50-52}$ By modifying the molecular models, the simulated NMR spectrum was gradually made consistent with the experiment NMR spectrum; at the same time, considering the detection results of FT-IR, only a small amount of aromatic carbon appeared in the structure. When the two spectra had a high degree of similarity, the molecular model was considered as reflecting the chemical characteristics of the sample accurately. Based on the information of the elements of samples, carbon and hydrogen are the most important elemental compositions, but restricted by the carbon numbers of average structural models, only the highest content of oxygen atoms is added to the average molecular structure, while sulfur and nitrogen atoms do not emerge.

However, limited by the average molecular weight, we paid more attention to the structural characteristics of the sample instead of molecular fragments during the establishment of models. The average chemical structure models of samples are shown in Figure 5; these had formulas of $\mathrm{C}_{26} \mathrm{H}_{40} \mathrm{O}$ and $\mathrm{C}_{28} \mathrm{H}_{44} \mathrm{O}$ for FS and $\mathrm{HC}$, respectively. The molecular masses of the two samples were 368 and $396 \mathrm{Da}$, consistent with the results of MALDI TOF MS. The experiment NMR spectra and the simulation spectra are also shown in Figure 5, and there was good similarity between the two spectra, indicating that the models could reflect the amber chemical structure.

From Figure 5, the two structural models contained multiple cycloalkane structures and almost no aliphatic chains. There were only a few methyl groups attached to the structure. In the chemical shift range of 95-150 ppm, there were no aromatic rings in the average molecular models, and there were only a few carbon-carbon double bonds, which appeared at the aromatic carbon chemical shift on the NMR spectra.

2.6. Molecular Model Optimization. To restore the state of resin structures in nature, Gaussian 16 was used to optimize the structure to a 3D form, which met the most stable state with the lowest energy. ${ }^{53,54}$ The structural optimization was based on DFT using the RB3LYP calculation method and the 6-311G (+ +) basis set. The 3D resin models are shown in Figure 6 (the source file of the models is included in the Supporting 
Table 3. Chemical Bond Length of the Average Resin Model

\begin{tabular}{|c|c|c|c|c|c|c|c|c|}
\hline sample & $\begin{array}{l}\text { chemical } \\
\text { bond }\end{array}$ & $\begin{array}{l}\text { bond length } \\
(\AA)\end{array}$ & $\begin{array}{l}\text { chemical } \\
\text { bond }\end{array}$ & $\begin{array}{c}\text { bond length } \\
(\AA)\end{array}$ & $\begin{array}{l}\text { chemical } \\
\text { bond }\end{array}$ & $\begin{array}{c}\text { bond length } \\
(\AA)\end{array}$ & $\begin{array}{l}\text { chemical } \\
\text { bond }\end{array}$ & $\begin{array}{c}\text { bond length } \\
(\AA)\end{array}$ \\
\hline \multirow[t]{17}{*}{ FS resin molecular model } & $\mathrm{C} 2-\mathrm{C} 1$ & 1.518 & C19-C5 & 1.503 & $\mathrm{H} 36-\mathrm{C} 12$ & 1.095 & $\mathrm{H} 53-\mathrm{C} 23$ & 1.093 \\
\hline & $\mathrm{C} 3-\mathrm{C} 2$ & 1.355 & $\mathrm{O} 20-\mathrm{C} 19$ & 1.464 & $\mathrm{H} 37-\mathrm{C} 13$ & 1.094 & $\mathrm{H} 54-\mathrm{C} 23$ & 1.093 \\
\hline & $\mathrm{C} 4-\mathrm{C} 1$ & 1.508 & $\mathrm{C} 21-\mathrm{C} 14$ & 1.545 & $\mathrm{H} 38-\mathrm{C} 14$ & 1.097 & $\mathrm{H} 55-\mathrm{C} 23$ & 1.091 \\
\hline & $\mathrm{C} 5-\mathrm{C} 4$ & 1.353 & $\mathrm{C} 22-\mathrm{C} 10$ & 1.539 & $\mathrm{H} 39-\mathrm{C} 14$ & 1.093 & $\mathrm{H} 56-\mathrm{C} 24$ & 1.091 \\
\hline & $\mathrm{C} 6-\mathrm{C} 2$ & 1.509 & C23-C18 & 1.541 & $\mathrm{H} 40-\mathrm{C} 15$ & 1.090 & $\mathrm{H} 57-\mathrm{C} 24$ & 1.094 \\
\hline & $\mathrm{C} 7-\mathrm{C} 6$ & 1.589 & $\mathrm{C} 24-\mathrm{C} 13$ & 1.541 & $\mathrm{H} 41-\mathrm{C} 15$ & 1.096 & $\mathrm{H} 58-\mathrm{C} 24$ & 1.095 \\
\hline & $\mathrm{C} 8-\mathrm{C} 3$ & 1.508 & C25-C6 & 1.551 & $\mathrm{H} 42-\mathrm{C} 17$ & 1.093 & $\mathrm{H} 59-\mathrm{C} 25$ & 1.092 \\
\hline & C9-C7 & 1.568 & $\mathrm{C} 26-\mathrm{C} 16$ & 1.558 & $\mathrm{H} 43-\mathrm{C} 17$ & 1.098 & $\mathrm{H} 60-\mathrm{C} 25$ & 1.091 \\
\hline & $\mathrm{C} 10-\mathrm{C} 8$ & 1.556 & C27-C9 & 1.560 & H44-C18 & 1.098 & $\mathrm{H} 61-\mathrm{C} 25$ & 1.089 \\
\hline & $\mathrm{C} 11-\mathrm{C} 9$ & 1.586 & $\mathrm{H} 28-\mathrm{C} 1$ & 1.098 & $\mathrm{H} 45-\mathrm{C} 19$ & 1.091 & $\mathrm{H} 62-\mathrm{C} 26$ & 1.089 \\
\hline & $\mathrm{C} 12-\mathrm{C} 11$ & 1.562 & $\mathrm{H} 29-\mathrm{C} 1$ & 1.096 & $\mathrm{H} 46-\mathrm{C} 19$ & 1.090 & $\mathrm{H} 63-\mathrm{C} 26$ & 1.092 \\
\hline & $\mathrm{C} 13-\mathrm{C} 12$ & 1.538 & $\mathrm{H} 30-\mathrm{C} 4$ & 1.079 & $\mathrm{H} 47-\mathrm{O} 20$ & 0.975 & H64-C26 & 1.088 \\
\hline & C14-C12 & 1.543 & H31-C6 & 1.100 & $\mathrm{H} 48-\mathrm{C} 21$ & 1.095 & $\mathrm{H} 65-\mathrm{C} 27$ & 1.093 \\
\hline & C15-C7 & 1.560 & $\mathrm{H} 32-\mathrm{C} 7$ & 1.092 & $\mathrm{H} 49-\mathrm{C} 21$ & 1.096 & H66-C27 & 1.091 \\
\hline & $\mathrm{C} 16-\mathrm{C} 11$ & 1.585 & $\mathrm{H} 33-\mathrm{C} 8$ & 1.099 & $\mathrm{H} 50-\mathrm{C} 22$ & 1.093 & $\mathrm{H} 67-\mathrm{C} 27$ & 1.086 \\
\hline & $\mathrm{C} 17-\mathrm{C} 10$ & 1.540 & $\mathrm{H} 34-\mathrm{C} 10$ & 1.094 & $\mathrm{H} 51-\mathrm{C} 22$ & 1.093 & & \\
\hline & $\mathrm{C} 18-\mathrm{C} 16$ & 1.577 & $\mathrm{H} 35-\mathrm{C} 11$ & 1.098 & $\mathrm{H} 52-\mathrm{C} 22$ & 1.091 & & \\
\hline \multirow[t]{18}{*}{ HC resin molecular model } & $\mathrm{C} 2-\mathrm{C} 1$ & 1.517 & $\mathrm{C} 20-\mathrm{C} 17$ & 1.580 & H38-C11 & 1.101 & H56-C23 & 1.095 \\
\hline & $\mathrm{C} 3-\mathrm{C} 2$ & 1.355 & $\mathrm{O} 21-\mathrm{C} 15$ & 1.461 & $\mathrm{H} 39-\mathrm{C} 12$ & 1.096 & $\mathrm{H} 57-\mathrm{C} 24$ & 1.092 \\
\hline & $\mathrm{C} 4-\mathrm{C} 1$ & 1.512 & $\mathrm{C} 22-\mathrm{C} 20$ & 1.575 & $\mathrm{H} 40-\mathrm{C} 12$ & 1.096 & $\mathrm{H} 58-\mathrm{C} 24$ & 1.096 \\
\hline & $\mathrm{C} 5-\mathrm{C} 4$ & 1.353 & $\mathrm{C} 23-\mathrm{C} 19$ & 1.542 & $\mathrm{H} 41-\mathrm{C} 13$ & 1.100 & $\mathrm{H} 59-\mathrm{C} 25$ & 1.093 \\
\hline & $\mathrm{C} 6-\mathrm{C} 2$ & 1.499 & $\mathrm{C} 24-\mathrm{C} 22$ & 1.537 & $\mathrm{H} 42-\mathrm{C} 14$ & 1.101 & $\mathrm{H} 60-\mathrm{C} 25$ & 1.093 \\
\hline & $\mathrm{C} 7-\mathrm{C} 6$ & 1.549 & $\mathrm{C} 25-\mathrm{C} 22$ & 1.539 & $\mathrm{H} 43-\mathrm{C} 15$ & 1.091 & $\mathrm{H} 61-\mathrm{C} 25$ & 1.093 \\
\hline & $\mathrm{C} 8-\mathrm{C} 3$ & 1.517 & C26-C20 & 1.543 & H44-C15 & 1.093 & H62-C26 & 1.093 \\
\hline & $\mathrm{C} 9-\mathrm{C} 7$ & 1.555 & $\mathrm{C} 27-\mathrm{C} 1$ & 1.545 & $\mathrm{H} 45-\mathrm{C} 16$ & 1.097 & H63-C26 & 1.090 \\
\hline & C10-C8 & 1.561 & $\mathrm{C} 28-\mathrm{C} 13$ & 1.540 & $\mathrm{H} 46-\mathrm{C} 17$ & 1.099 & H64-C26 & 1.091 \\
\hline & C11-C9 & 1.547 & C29-C14 & 1.542 & $\mathrm{H} 47-\mathrm{C} 18$ & 1.092 & $\mathrm{H} 65-\mathrm{C} 27$ & 1.092 \\
\hline & $\mathrm{C} 12-\mathrm{C} 11$ & 1.536 & $\mathrm{H} 30-\mathrm{C} 1$ & 1.101 & $\mathrm{H} 48-\mathrm{C} 18$ & 1.089 & $\mathrm{H} 66-\mathrm{C} 27$ & 1.092 \\
\hline & $\mathrm{C} 13-\mathrm{C} 12$ & 1.539 & $\mathrm{H} 31-\mathrm{C} 4$ & 1.080 & H49-C18 & 1.088 & $\mathrm{H} 67-\mathrm{C} 27$ & 1.092 \\
\hline & C14-C13 & 1.553 & H32-C6 & 1.093 & H50-C19 & 1.098 & H68-C28 & 1.091 \\
\hline & $\mathrm{C} 15-\mathrm{C} 5$ & 1.505 & H33-C6 & 1.101 & $\mathrm{H} 51-\mathrm{C} 20$ & 1.097 & $\mathrm{H} 69-\mathrm{C} 28$ & 1.095 \\
\hline & C16-C11 & 1.564 & $\mathrm{H} 34-\mathrm{C} 7$ & 1.100 & $\mathrm{H} 52-\mathrm{O} 21$ & 0.975 & $\mathrm{H} 70-\mathrm{C} 28$ & 1.093 \\
\hline & $\mathrm{C} 17-\mathrm{C} 10$ & 1.560 & $\mathrm{H} 35-\mathrm{C} 8$ & 1.103 & $\mathrm{H} 53-\mathrm{C} 22$ & 1.098 & $\mathrm{H} 71-\mathrm{C} 29$ & 1.095 \\
\hline & $\mathrm{C} 18-\mathrm{C} 16$ & 1.542 & H36-C9 & 1.095 & H54-C23 & 1.090 & $\mathrm{H} 72-\mathrm{C} 29$ & 1.090 \\
\hline & C19-C10 & 1.576 & $\mathrm{H} 37-\mathrm{C} 10$ & 1.096 & $\mathrm{H} 55-\mathrm{C} 23$ & 1.089 & $\mathrm{H} 73-\mathrm{C} 29$ & 1.090 \\
\hline
\end{tabular}

Information), and to show the characteristics of the molecular model clearly, the serial numbers of each atom are marked in the model. As shown in Figure 6, the molecular model is affected by the bond angle, and the models are curved.

Table 3 lists the bond length of each chemical bond in the amber molecular models. In the models, the length of the $\mathrm{C}-\mathrm{H}$ bond was around $1.09 \AA$, which was the shortest chemical bond. The $\mathrm{C}=\mathrm{C}$ chemical bond length was approximately $1.35 \AA$, slightly shorter than the $\mathrm{C}-\mathrm{C}$ bond, which was the longest bond type in the model (around 1.55 $\AA$ ). This phenomenon indicates that the $\mathrm{C}-\mathrm{C}$ bond was the weakest chemical bond in the structure, and it was more prone to breakage compared with other bonds.

2.7. Calculation of Binding Energy. To evaluate the intermolecular interactions between resins and the other compounds in oil, component docking was performed in Autodock 4.2, a commonly used molecular modeling package, which can calculate the binding state of two molecules.

$\mathrm{N}$-Octadecane and dimethyl naphthalene were selected to represent the saturated hydrocarbon and aromatic hydrocarbon compounds in crude oil. According to our previous work, the molecular model of Huoshiling (HSL) bitumen was used to substitute macromolecule geological organic matter like asphaltene. $^{21}$ The 2D HSL molecular model was optimized to a $3 \mathrm{D}$ model following the same method as in the amber molecules.

The structures of resin molecules bonded with $n$-octadecane, dimethyl naphthalene, and HSL molecules are shown in Figure 7. The binding energy (Gibbs free energy) of each model is listed in the figure. From Figure 7, the n-octadecane molecule was distorted by the intermolecule force and distributed at the periphery of the resin molecules; the dimethyl naphthalene molecule was also distributed on the outside of the resin molecules like the n-octadecane. The resin molecules were closely bound with the bitumen molecules and were located in the cavity formed by aliphatic chains and aromatic clusters in the bitumen models. In addition, the binding energy between $n$ octadecane and dimethyl naphthalene models and the resin models was positive, while the binding energy of HSL bitumen and FS resin was $-7.01 \mathrm{kcal} / \mathrm{mol}$ and that of HSL bitumen and $\mathrm{HC}$ resin was $-8.52 \mathrm{kcal} / \mathrm{mol}$. The negative Gibbs free energy value shows an energy release during docking, and the lower the value, the easier to bind. This phenomenon indicates that under geological conditions, resin molecules are more likely to bind with bitumen than with hydrocarbons. This demonstrates that 


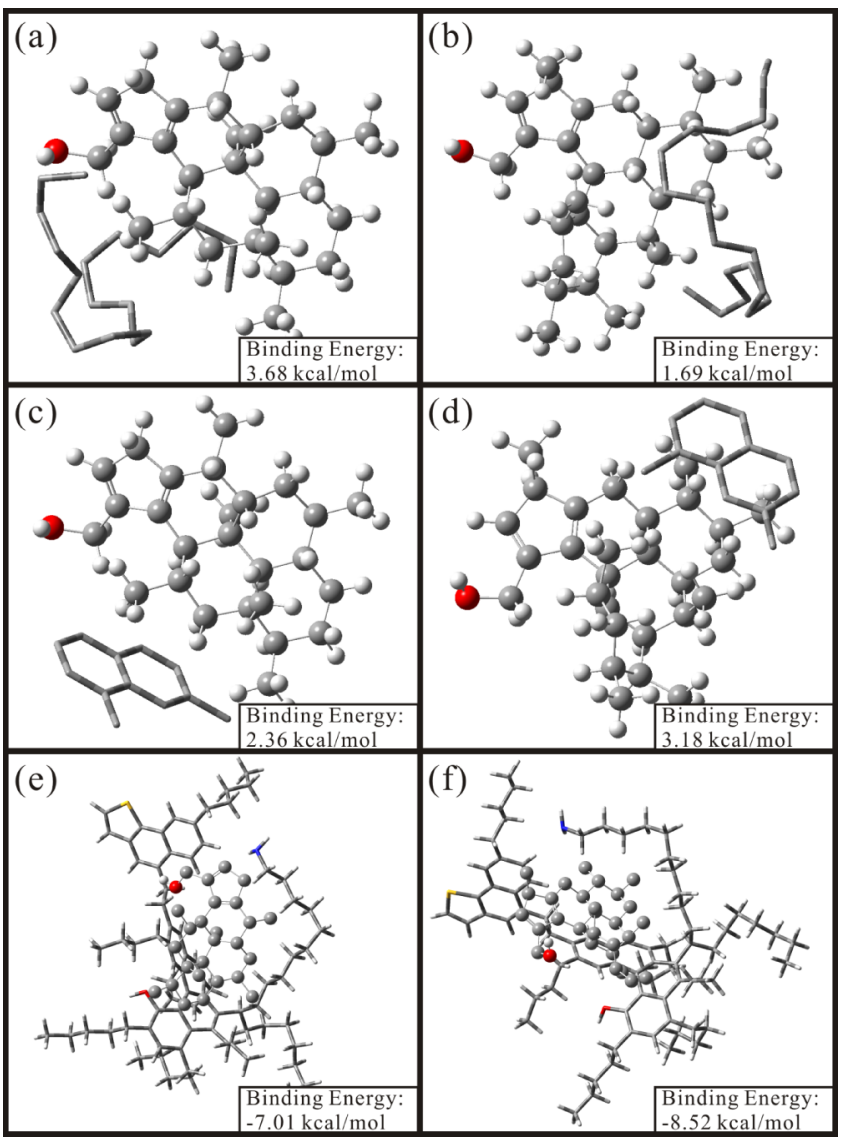

Figure 7. Images of docked poses for molecules. (a) FS resin: $\mathrm{C}_{18} \mathrm{H}_{38}$; (b) $\mathrm{HC}$ resin: $\mathrm{C}_{18} \mathrm{H}_{38}$; (c) FS resin: $\mathrm{C}_{12} \mathrm{H}_{12}$; (d) HC resin: $\mathrm{C}_{12} \mathrm{H}_{12}$; (e) FS resin: HSL bitumen; (f) HC resin: HSL bitumen. The binding energy (Gibbs free energy) of resin molecules and bitumen molecules is negative, while the binding energy of hydrocarbons is positive, indicating that the resin bond with bitumen molecules is more stable than for hydrocarbon compounds.

this method is suitable for studying the interactions among geological organic matter.

\section{CONCLUSIONS}

In this study, in two coal samples collected from FS and HC coal samples, natural solid amber was separated and resin was extracted from the coal. Following the detection of structural parameters and molecular mass, molecular simulation research was performed, and the following conclusions were obtained:

(1) The study characterized the chemical structure of natural solid amber, which was dominated by cycloalkanes with a small amount of aromatic carbon. There was a small number of methyl, carbonyl, and carboxyl groups and almost no aliphatic chains in the structure.

(2) The resin compound molecular mass distribution was mainly within the range of 99-750 Da, with the highest compound content around $370 \mathrm{Da}$. Therefore, the average resin molecular model used this relative mass. Based on the results of solid-state NMR, two average molecular models of resin were established. The molecular models were consistent with the NMR results and could reflect the structural characteristics of amber and resin accurately.

(3) The models were optimized in three dimensions based on DFT, and the most stable state under natural conditions was obtained. Meanwhile, the length of each chemical bond in models was calculated to evaluate the stability of the chemical bonds in the models.

(4) The intermolecular interaction between resin and the other oil components was calculated in Autodock 4.2, and the binding energy indicated that the binding of resin and bitumen molecules was more stable than saturated and aromatic hydrocarbon compounds.

\section{MATERIALS AND METHODS}

4.1. Materials. The amber samples in this study were collected from the FS and HC coal samples. Figure 8 shows that

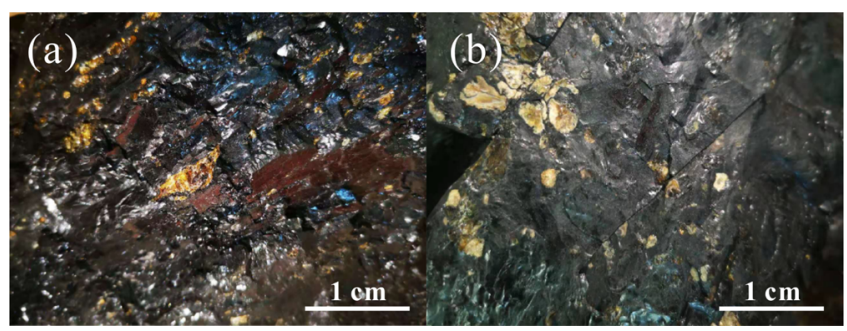

Figure 8. Images of FS (a) and HC (b) coal samples; the black solid is coal and the yellow transparent solids are the amber sample particles in the coal.

amber is distributed in the coal. The coal samples were broken into small pieces, and the amber fragments were picked by tweezers without organic solvents. Amber was crushed to 120 mesh (particle size $\sim 0.125 \mathrm{~mm}$ ) for the organic elemental analysis and the solid-state NMR analysis.

After the separation of amber, the soluble organic matter was extracted from the coals using dichloromethane and methanol in the volume ratio of 93:7 for $72 \mathrm{~h}$. Column chromatography was used to separate the soluble components into four parts: saturated hydrocarbons, aromatic hydrocarbons, resins, and asphaltenes (SARA). MALDI TOF MS was used to determine the resin content and relative molecular mass.

4.2. Analysis. In this study, to establish the average molecular structure of resin, elemental analysis and solid-state ${ }^{13} \mathrm{C}$ NMR spectroscopy were used to study the amber, and MALDI TOF MS was used to analyze the relative molecular mass of resins. The analyses are presented in greater detail as follows:

(1) Relative elemental contents ( $\mathrm{C}, \mathrm{H}, \mathrm{N}, \mathrm{O}$, and S) were analyzed by using an Elementar Vario EL III. Five organic elements were tested separately, and the chemical components of amber samples were obtained.

(2) FT-IR spectroscopy was performed on a Bruker Vertex-70 V Fourier transform infrared spectrometer (GIG, CAS) using the $\mathrm{KBr}$ pressed disk technique. The spectra were collected in the range of $4000-400 \mathrm{~cm}^{-1}$ with 64 scans and the resolution was $4 \mathrm{~cm}^{-1}$.

(3) Solid-state ${ }^{13} \mathrm{C}$ NMR analysis of amber samples was performed on a Bruker AVANCE II $600 \mathrm{MHz}$ instrument using a $4 \mathrm{~mm}$ probe at a spinning speed of $14,000 \mathrm{~Hz}$ and a spectral width of $150.6 \mathrm{M} \mathrm{Hz}$, as per the DP/MAS method. The number of scans of the method was $5 \mathrm{k}$.

(4) The resin molecular masses were detected by using a TOF/TOF 5800 system (SCIEX) in the positive ion mode. The MALDI stage was operated in the continuous 
motion mode. The mass range of the instrument was from 100 to $4000 \mathrm{Da}$.

\section{ASSOCIATED CONTENT}

\section{(5) Supporting Information}

The Supporting Information is available free of charge at https://pubs.acs.org/doi/10.1021/acsomega.1c04342.

Information of two resin molecules including atomic coordinates, bond length, bond angle, and dihedral angle (PDF)

\section{AUTHOR INFORMATION}

\section{Corresponding Author}

Yan-Rong Zou - State Key Laboratory of Organic Geochemistry, Guangzhou Institute of Geochemistry, Guangzhou 510640, China; CAS Center for Excellence in Deep Earth Science, Guangzhou 510640, China; ๑ orcid.org/0000-0003-4071-6233; Email: zouyr@ gig.ac.cn

\section{Authors}

Tian Liang - State Key Laboratory of Organic Geochemistry, Guangzhou Institute of Geochemistry, Guangzhou 510640, China; CAS Center for Excellence in Deep Earth Science, Guangzhou 510640, China; University of Chinese Academy of Sciences, Beijing 100049, China

Zhao-Wen Zhan - State Key Laboratory of Organic Geochemistry, Guangzhou Institute of Geochemistry, Guangzhou 510640, China; CAS Center for Excellence in Deep Earth Science, Guangzhou 510640, China; - orcid.org/0000-0001-7336-4962

Complete contact information is available at: https://pubs.acs.org/10.1021/acsomega.1c04342

\section{Notes}

The authors declare no competing financial interest.

\section{ACKNOWLEDGMENTS}

This work was financially supported by the Strategic Priority Research Program of the Chinese Academy of Sciences (XDA14010102) and the State Key Laboratory of Organic Geochemistry Project (grant no. SKLOG2020-1). Dr. Wu Li (China University of Mining and Technology) guided the establishment of molecular models. Scripps Research Institute provided the software of Autodock 4.2. Thanks to the editor and reviewers for their help with this paper.

\section{REFERENCES}

(1) Jewell, D. M.; Weber, J. H.; Bunger, J. W.; Plancher, H.; Latham, D. R. Ion-Exchange, Coordination, and Adsorption Chromatographic Separation of Heavy-End Petroleum Distillates. Anal. Chem. 1972, 44, 1391-1395.

(2) Jewell, D. M.; Albaugh, E. W.; Davis, B. E.; Ruberto, R. G. Integration of Chromatographic and Spectroscopic Techniques for the Characterization of Tesidual Oils. Ind. Eng. Chem. Fundam. 1974, 13, 278-282.

(3) Pelet, R.; Behar, F.; Monin, J. C. Resins and asphaltenes in the generation and migration of petroleum. Org. Geochem. 1986, 10, 481498.

(4) Strachan, M. G.; Alexander, R.; Subroto, E. A.; Kagi, R. I. Costraints upon the use of 24-ethylcholestane diastereomer ratios as indicators of the maturity of petroleum. Org. Geochem. 1989, 14, 423432.
(5) Aguiar, J. I. S.; Mansur, C. R. E. Study of the interaction between asphaltenes and resins by microcalorimetry and ultraviolet-visible spectroscopy. Fuel 2015, 140, 462-469.

(6) Lashkarbolooki, M.; Ayatollahi, S. Effects of asphaltene, resin and crude oil type on the interfacial tension of crude oil/brine solution. Fuel 2018, 223, 261-267.

(7) Bava, Y. B.; Geronés, M.; Giovanetti, L. J.; Andrini, L.; Erben, M. F. Speciation of sulphur in asphaltenes and resins from Argentinian petroleum by using XANES spectroscopy. Fuel 2019, 256, 115952.

(8) Klein, G. C.; Angström, A.; Rodgers, R. P.; Marshall, A. G. Use of Saturates/Aromatics/Resins/Asphaltenes (SARA) Fractionation To Determine Matrix Effects in Crude Oil Analysis by Electrospray Ionization Fourier Transform Ion Cyclotron Resonance Mass Spectrometry. Energy Fuels 2006, 20, 668-672.

(9) Zhu, D.-Y.; Deng, Z.-H.; Chen, S.-W. A review of nuclear magnetic resonance (NMR) technology applied in the characterization of polymer gels for petroleum reservoir conformance control. Pet. Sci. 2021, DOI: $10.1016 /$ j.petsci.2021.09.008. , oline

(10) Montes, L. F.; Oliveira, E. C. S.; Neto, Á. C.; Menezes, S. M. C.; Castro, E. R. V.; Barbosa, L. L. Low-field NMR: A new alternative to determine the aromatic content of petroleum distillates. Fuel 2019, 239, 413-420.

(11) Koots, J. A.; Speight, J. G. Relation of petroleum resins to asphaltenes. Fuel 1975, 54, 179-184.

(12) Murgich, J.; Rodríguez, R. M.; Aray, Y. Molecular Recognition and Molecular Mechanics of Micelles of Some Model Asphaltenes and Resins. Energy Fuels 1996, 10, 68-76.

(13) Alvarez-Ramirez, F.; Ramirez-Jaramillo, E.; Ruiz-Morales, Y. Calculation of the Interaction Potential Curve between AsphalteneAsphaltene, Asphaltene-Resin, and Resin-Resin Systems Using Density Functional Theory. Energy Fuels 2006, 20, 195-204.

(14) Castellano, O.; Gimon, R.; Soscun, H. Theoretical Study of the $\sigma$ $\pi$ and $\pi$ - $\pi$ Interactions in Heteroaromatic Monocyclic Molecular Complexes of Benzene, Pyridine, and Thiophene Dimers: Implications on the Resin-Asphaltene Stability in Crude Oil. Energy Fuels 2011, 25, 2526-2541.

(15) Mousavi, M.; Abdollahi, T.; Pahlavan, F.; Fini, E. H. The influence of asphaltene-resin molecular interactions on the colloidal stability of crude oil. Fuel 2016, 183, 262-271.

(16) Wang, P.; Dong, Z.-j.; Tan, Y.-q.; Liu, Z.-y. Investigating the Interactions of the Saturate, Aromatic, Resin, and Asphaltene Four Fractions in Asphalt Binders by Molecular Simulations. Energy Fules 2015, 29, 112-121.

(17) Mullins, O. C. The Modified Yen Model. Energy Fuels 2010, 24, 2179-2207.

(18) Orendt, A. M.; Pimienta, I. S. O.; Badu, S. R.; Solum, M. S.; Pugmire, R. J.; Facelli, J. C.; Locke, D. R.; Chapman, K. W.; Chupas, P. J.; Winans, R. E. Three-Dimensional Structure of the Siskin Green River Oil Shale Kerogen Model: A Comparison between Calculated and Observed Properties. Energy Fuels 2013, 27, 702-710.

(19) Chen, L.; Meyer, J.; Campbell, T.; Canas, J.; Betancourt, S. S.; Dumont, H.; Forsythe, J. C.; Mehay, S.; Kimball, S.; Hall, D. L.; Nighswander, J.; Peters, K. E.; Zuo, J. Y.; Mullins, O. C. Applicability of simple asphaltene thermodynamics for asphaltene gradients in oilfield reservoirs: The Flory-Huggins-Zuo Equation of State with the YenMullins model. Fuel 2018, 221, 216-232.

(20) Gao, Y.; Zou, Y.-R.; Liang, T.; Peng, P. a. Jump in the structure of Type I kerogen revealed from pyrolysis and ${ }^{13} \mathrm{C}$ DP MAS NMR. Org. Geochem. 2017, 112, 105-118.

(21) Liang, T.; Zou, Y.-R.; Zhan, Z.-W.; Lin, X.-H.; Shi, J.; Peng, P. a. An evaluation of kerogen molecular structures during artificial maturation. Fuel 2020, 265, 116979.

(22) Trewhella, M. J.; Poplett, I. J. F.; Grint, A. Structure of Green River oil shale kerogen Determination using solid state ${ }^{13} \mathrm{C} \mathrm{nmr}$ spectroscopy. Fuel 1986, 65, 541-546.

(23) Siskin, M.; Scouten, C. G.; Rose, K. D.; Aczel, T.; Colgrove, S. G.; Pabst, R. E. Detailed structural characterization of the organic material in Rundle Ramsay crossing and Green River oil shales. In Composition, 
Geochemistry and Conversion of Oil Shales; Snape, C., Ed.; Kluwer Academic: Boston 1995, pp, 143.

(24) Yen, T. F.; Erdman, J. G.; Pollack, S. S. Investigation of the Structure of Petroleum Asphaltenes by X-Ray Diffracion. Anal. Chem. 1961, 33, 1587-1594.

(25) Dickie, J. P.; Yen, T. F. Macrostructures of the Asphaltic Fractions by Various Instrumental Methods. Anal. Chem. 1967, 39, $1847-1852$.

(26) Murgich, J.; Rodríguez M, J.; Izquierdo, A.; Carbognani, L.; Rogel, E. Interatomic Interactions in the Adsorption of Asphaltenes and Resins on Kaolinite Calculated by Molecular Dynamics. Energy Fuels 1998, 12, 339-343.

(27) Murgich, J.; Abanero, J. A.; Strausz, O. P. Molecular Recognition in Aggregates Formed by Asphaltene and Resin Molecules from the Athabasca Oil Sand. Energy Fuels 1999, 13, 278-286.

(28) Coelho, R. R.; Hovell, I.; de Mello Monte, M. B.; Middea, A.; de Souza, A. L. Characterisation of aliphatic chains in vacuum residues (VRs) of asphaltenes and resins using molecular modelling and FTIR techniques. Fuel Process. Technol. 2006, 87, 325-333.

(29) Li, T.; Xu, J.; Zou, R.; Feng, H.; Li, L.; Wang, J.; Stuart, M. A. C.; Guo, X. Resin from Liaohe Heavy Oil: Molecular Structure, Aggregation Behavior, and Effect on Oil Viscosity. Energy Fuels 2018, 32, 306-313.

(30) Anderson, K. B.; Crelling, J. C. Amber, Resinite and Fossil Resins; ACS Symposium Series; American Chemical Society: Washington USA, 1995; Vol. 617.

(31) Matuszewska, A.; Czaja, M. Aromatic compounds in molecular phase of Baltic amber-synchronous luminescence analysis. Talanta 2002, 56, 1049-1059.

(32) Wang, Y.; Jiang, W.; Feng, Q.; Lu, H.; Zhou, Y.; Liao, J.; Wang, Q.; Sheng, G. Identification of 15-nor-cleroda-3,12-diene in a Dominican amber. Org. Geochem. 2017, 113, 90-96.

(33) Park, J.; Yun, E.; Kang, H.; Ahn, J.; Kim, G. IR and py/GC/MS examination of amber relics excavated from 6th century royal tomb in Korean Peninsula. S. Asian Arts 2016, 165, 114-119.

(34) Menor-Salván, C.; Simoneit, B. R. T.; Ruiz-Bermejo, M.; Alonso, $\mathrm{J}$. The molecular composition of Cretaceous ambers: Identification and chemosystematic relevance of 1,6-dimethyl-5-alkyltetralins and related bisnorlabdane biomarkers. Org. Geochem. 2016, 93, 7-21.

(35) Lille, Ü.; Heinmaa, I.; Pehk, T. Molecular model of Estonian kukersite kerogen evaluated by 13C MAS NMR spectra. Fuel 2003, 82, 799-804.

(36) van der Werf, I. D.; Fico, D.; De Benedetto, G. E.; Sabbatini, L. The molecular composition of Sicilian amber. Microchem. J. 2016, 125, $85-96$.

(37) Wang, Y.; Jiang, W.; Feng, Q.; Lu, H.; Zhou, Y.; Liao, J.; Wang, Q.; Sheng, G. Identification of 15-nor-cleroda-3,12-diene in a Dominican amber. Org. Geochem. 2017, 113, 90-96.

(38) Anderson, K. B.; Winans, R. E.; Botto, R. E. The nature and fate of natural resins in the geosphere-II. Identification, classification and nomenclature of resinites. Org. Geochem. 1992, 18, 829-841.

(39) Cunningham, A.; Gay, I. D.; Oehlschlager, A. C.; Langenheim, J. $\mathrm{H} .{ }^{13} \mathrm{C}$ NMR and IR analyses of structure, aging and botanical origin of dominican and mexican ambers. Phytochemistry 1983, 22, 965-968.

(40) Menor-Salván, C.; Simoneit, B. R. T.; Ruiz-Bermejo, M.; Alonso, $\mathrm{J}$. The molecular composition of Cretaceous ambers: Identification and chemosystematic relevance of 1,6-dimethyl-5-alkyltetralins and related bisnorlabdane biomarkers. Org. Geochem. 2016, 93, 7-21.

(41) Martínez-Richa, A.; Vera-Graziano, R.; Rivera, A.; JosephNathan, P. A solid-state ${ }^{13} \mathrm{C}$ NMR analysis of ambers. Polym 2000, 41, $743-750$.

(42) Alstadt, K. N.; Katti, D. R.; Katti, K. S. An in situ FTIR step-scan photoacoustic investigation of kerogen and minerals in oil shale. $S$. Asian Arts 2012, 89, 105-113.

(43) Lis, G. P.; Mastalerz, M.; Schimmelmann, A.; Lewan, M. D.; Stankiewicz, B. A. FTIR absorption indices for thermal maturity in comparison with vitrinite reflectance R0 in type-II kerogens from Devonian black shales. Org. Geochem. 2005, 36, 1533-1552.
(44) Jiang, J.; Zhang, S.; Longhurst, P.; Yang, W.; Zheng, S. Molecular structure characterization of bituminous coal in Northern China via XRD, Raman and FTIR spectroscopy. S. Asian Arts 2021, 255, 119724.

(45) Mao, J.; Fang, X.; Lan, Y.; Schimmelmann, A.; Mastalerz, M.; Xu, L.; Schmidt-Rohr, K. Chemical and nanometer-scale structure of kerogen and its change during thermal maturation investigated by advanced solid-state ${ }^{13} \mathrm{C}$ NMR spectroscopy. Geochim. Cosmochim. Acta 2010, 74, 2110-2127.

(46) Burdelnaya, N.; Bushnev, D.; Mokeev, M.; Dobrodumov, A. Experimental study of kerogen maturation by solid-state ${ }^{13} \mathrm{C}$ NMR spectroscopy. Fuel 2014, 118, 308-315.

(47) Guan, X.-H.; Liu, Y.; Wang, D.; Wang, Q.; Chi, M.-S.; Liu, S.; Liu, C.-G. Three-Dimensional Structure of a Huadian Oil Shale Kerogen Model: An Experimental and Theoretical Study. Energy Fuels 2015, 29, $4122-4136$

(48) Tong, J.; Jiang, X.; Han, X.; Wang, X. Evaluation of the macromolecular structure of Huadian oil shale kerogen using molecular modeling. Fuel 2016, 181, 330-339.

(49) Mao, J.-D.; Schmidt-Rohr, K. Accurate Quantification of Aromaticity and Nonprotonated Aromatic Carbon Fraction in Natural Organic Matter by ${ }^{13} \mathrm{C}$ Solid-State Nuclear Magnetic Resonance. Environ. Sci. Technol. 2004, 38, 2680-2684.

(50) ACD/Labs. 2016. http://www.acdlabs.com/resources/ freeware/chemsketch.

(51) Cherwell Scientific Publishing. gNMR, version 5.0.6-DEMO; Cherwell Scientific Publishing, 2011.

(52) Huang, Z.; Liang, T.; Zhan, Z.-W.; Zou, Y.-R.; Li, M.; Peng, P. a. Chemical structure evolution of kerogen during oil generation. Mar. Pet. Geol. 2018, 98, 422-436.

(53) Frisch, M. J.; Trucks, G. W.; Schlegel, H. B.; Scuseria, G. E.; Robb, M. A.; Cheeseman, J. R.; Scalmani, G.; Barone, V.; Petersson, G. A.; Nakatsuji, H.; Li, X.; Caricato, M.; Marenich, A. V.; Bloino, J.; Janesko, B. G.; Gomperts, R.; Mennucci, B.; Hratchian, H. P.; Ortiz, J. V.; Izmaylov, A. F.; Sonnenberg, J. L.; Williams-Young, D.; Ding, F.; Lipparini, F.; Egidi, F.; Goings, J.; Peng, B.; Petrone, A.; Henderson, T.; Ranasinghe, D.; Zakrzewski, V. G.; Gao, J.; Rega, N.; Zheng, G.; Liang, W.; Hada, M.; Ehara, M.; Toyota, K.; Fukuda, R.; Hasegawa, J.; Ishida, M.; Nakajima, T.; Honda, Y.; Kitao, O.; Nakai, H.; Vreven, T.; Throssell, K.; Montgomery, J. A., Jr.; Peralta, J. E.; Ogliaro, F.; Bearpark, M. J.; Heyd, J. J.; Brothers, E. N.; Kudin, K. N.; Staroverov, V. N.; Keith, T. A.; Kobayashi, R.; Normand, J.; Raghavachari, K.; Rendell, A. P.; Burant, J. C.; Iyengar, S. S.; Tomasi, J.; Cossi, M.; Millam, J. M.; Klene, M.; Adamo, C.; Cammi, R.; Ochterski, J. W.; Martin, R. L.; Morokuma, K.; Farkas, O.; Foresman, J. B.; Fox, D. J. Gaussian 16, Revision B.01; Gaussian, Inc.: Wallingford, C. T, 2016.

(54) Dennington, R.; Keith Todd, A.; John, M. M. GaussView, version 6; Semichem Inc. Shawnee Mission, K. S., 2016. 